\title{
Outdoor personalizado: base de dados online e perspectivas de análises
}

Francisco Mesquita*, Fernanda Viana** e Eduardo Zilles Borba***

Resumo: A publicidade exterior tem crescido consideravelmente nas duas últimas décadas. Este crescimento deve-se a vários factores, entre os quais salientamos a crescente mobilidade diária das pessoas e a tecnologia de impressão digital disponível no mercado.

A expressão mais espectacular da publicidade fora de portas é o outdoor personalizado, conceito proposto e representativo dos grandes cartazes de rua que se adaptam a determinado local e que por esta razão são imagens únicas no espaço público.

O presente trabalho focaliza-se no outdoor personalizado, tendo como base da reflexão uma base de dados online deste tipo de imagens. Pretende-se, neste contexto, problematizar dois importantes factores estruturantes desse corpus: parâmetros de localização no meio urbano e transposição do outdoor do espaço físico para o virtual.

Palavras-chave: publicidade exterior, outdoor personalizado, localização, espaço virtual, bigposter.

\section{Introdução}

No âmbito do presente artigo interessa-nos aflorar algumas questões sobre publicidade exterior e, particularmente, sobre os grandes cartazes de rua que encontramos no espaço urbano.

O conceito por nós proposto para designar este tipo de imagens de grande formato é o de outdoor personalizado. Outdoor, uma vez que é a terminologia utilizada no nosso país para significar os grandes cartazes de rua padronizados; personalizado, na medida em que este tipo de imagens estabelecem um dialogo perfeito com determinado local onde se inserem. Ou seja, são pensadas e produzidas para se adaptarem a um local e não a qualquer outro, tal como acontece com o outdoor padronizado.

* Doutorado pela Universidade do Minho e Professor Auxiliar da Universidade Fernando Pessoa (fmes@ufp.edu.pt).

** Doutoranda na Universidade do Minho e Professora Assistente na Universidade Fernando Pessoa (fviana@ufp.edu.pt).

*** Doutorando na Universidade Fernando Pessoa (ezb@ezb.com.br). 
Outro dos intuitos desta proposta prende-se com a construção de uma base de dados online de outdoors personalizados (http://bigposter.ufp.pt - brevemente online). Esta base de dados digital organiza, preserva e torna acessível as "imagens" que estes grandes cartazes nos transmitem. Imagens essas que fazem parte da memória colectiva de todos nós por nos contarem a história de um produto, marca ou serviço, mas “imagens" também representativas de outras histórias (da tecnologia, da estética e das mentalidades) de determinada época.

A localização do outdoor personalizado no espaço urbano é outra das questões de interesse. Neste contexto, apresenta-se um estudo que nos fornece parâmetros gerais da ocupação do espaço urbano deste tipo de imagens, na cidade do Porto.

Por último, focar-nos-emos na transposição do espaço físico para o virtual do outdoor personalizado. São expostas linhas de actuação nas plataformas tecnológicas e directrizes para a construção de um modelo virtual representativo do real (físico).

No contexto assinalado, os objectivos desta proposta de trabalho estão focalizados no outdoor personalizado. Assim sendo, consideramos:

- Uma breve reflexão sobre a semântica da terminologia que propomos - o outdoor personalizado;

- a apresentação de uma base de dados digital e online de outdoors personalizados;

- um caso real de localização no espaço urbano desta tipologia de "imagens";

- uma metodologia para a transposição do espaço físico para o virtual.

Uma vez que se trata de um conceito novo, por nós aduzido, torna-se necessário explicar o que entendemos ser o outdoor personalizado, para que melhor consigamos fazer entender o nosso objecto de estudo. Em tal objectivo se circunscreve a necessidade de evidenciar o critério de localização do outdoor personalizado no espaço, bem como a metodologia de transposição do físico para o virtual. No que à localização do nosso objecto de estudo diz respeito, procura-se entender o seu enquadramento no espaço urbano. Relativamente à metodologia de transposição, pretende-se simular no espaço virtual a experiência sensorial entre receptor e outdoor personalizado que decorre no espaço físico. Para tal, utilizamos a fotografia, o vídeo e a infografia, três formas de expressão visual que se complementam e enriquecem, de forma a tornar mais rico o corpus proposto.

É nossa intenção que a base de dados online de outdoors personalizados que propomos possa ser objecto de estudos em múltiplas áreas e que suscite, também, o interesse de profissionais da área.

Além de preservar a memória histórica e o interesse que daí advém, interessa, ainda, que o corpus representativo destas "imagens" seja alvo de olhares múltiplos. Isto, na medida em que essas imagens manifestam, também, posturas variadas: estéticas, sociais, culturais e económicas; campos, entre outros, que a publicidade reflecte. 


\section{Breve enquadramento do outdoor personalizado}

Se observarmos a evolução das fórmulas publicitárias dos últimos anos, particularmente a partir de meados da última década do século XX, notamos um crescimento notável da publicidade exterior. Cada vez mais sofisticada e envolvendo vários formatos e tecnologias, a publicidade fora de portas (Out-Of-Home, $\mathrm{OOH})$ tem-se imposto, marcando presença contínua no quotidiano do homem urbano.

Da grande variedade de formas, suporte, formatos e processo de produção que a publicidade exterior envolve, interessa-nos focalizar a nossa atenção nos grandes cartazes de rua, entre nós denominados outdoors. Nesta categoria da publicidade exterior o nosso interesse dirige-se para os outdoors personalizados, conceito por nós aduzido e proposto por Mesquita (2006). Pretende-se com esta terminologia referir os grandes cartazes que são produzidos para um local específico. Ou seja, a produção desta tipologia de grandes cartazes exige que idealização, design, produção e montagem se adeqúem às características do respectivo espaço a ocupar. Face a estes aspectos, as imagens resultantes são únicas, gozando de um carácter de personalização que não existe no outdoor convencional ( $8 \times 3 \mathrm{~m}, 4 \times 3 \mathrm{~m})$. Dir-se-á, como característica complementar e definidora desta categoria de publicidade exterior, que este tipo de imagens estabelece um diálogo perfeito com o espaço que ocupam: empenas, fachadas de edifícios e outros locais públicos.

O outdoor personalizado não é meramente um megacartaz. Trata-se, sim, de um meio original com características técnico-estéticas próprias e possuindo a sua própria gramática articulada internamente (textos e imagens e outros elementos gráficos) e externamente (cartazes e outros elementos da paisagem).

\subsection{Base de dados online de outdoors personalizados}

A preservação da memória das sociedades tem acompanhado o percurso do homem. Os museus são casos paradigmáticos desta actuação. Lembrando Le Goff (1984: 98), “(...) com tudo o que, pertencendo ao Homem, depende do homem, serve o homem, exprime o homem, demonstra presença, a actividade, os gostos e a maneira de ser do homem", ou Jahlly (1995: 13) quando afirma que a publicidade "(...) ascendeu a um plano de proeminência na sociedade moderna, enquanto discurso através e acerca dos objectos”.

O homem contemporâneo, sendo o alvo destas imagens, é também produto sociológico dos seus significados. No que ao cartaz diz respeito ele "constrói reflexos condicionados, slogans e estereótipos que se imprimem na cultura individual e, por isso, adquirem valor autónomo, independente do seu assunto, Moles (1969). Podemos assinalar, neste contexto, que a publicidade é uma influente instituição de sociabilização, nas sociedades modernas (Jhally 1995). Por conseguinte, o outdoor personalizado exerce um importante papel neste contexto, quer pela sua presença cada vez mais frequente, quer pela espectacularidade dos seus formatos, do tamanho das imagens que veicula, bem como de uma estética própria que lhe está associada.

Por conseguinte, e como resposta às considerações anteriores, criámos o bigposter, um portal online que reúne e preserva as "imagens" difundidas pelos outdoors no espaço urbano (http://bigposter.ufp.pt). 


\section{Reflexão sobre o outdoor personalizado na cidade do Porto}

Centrado numa reflexão sobre os cartazes de grande formato no Porto, Viana (2009), este artigo considera todos os outdoors personalizados presentes no primeiro trimestre de 2009 e também o seu enquadramento. Efectuámos uma análise sobre as deslocações diárias apoiada em diversos estudos sobre as movimentações viárias e locais de trajecto pedonal $^{1}$, os quais permitiram identificar zonas específicas, vias movimentadas, percursos habituais e tipo de público (pedestre ou automobilizado) organizados em mapas de densidade de circulação pedonal e rodoviária e zonas urbanas de actividade: acesso a transportes colectivos, comércio a retalho, escritórios/serviços, industrial, desporto, lazer e diversão nocturna (ver Figura 1). A amostra, constituída por sessenta outdoors personalizados, foi categorizada de acordo com o tipo de produto e/ou serviço anunciado, segundo a Classificação Portuguesa de Actividades Económicas (CAE), conforme Tabela 1.

Tabela 1. Categorização dos outdoors personalizados em estudo de acordo com o CAE

\begin{tabular}{|c|c|c|c|c|c|c|c|c|c|c|}
\hline Zonas / Categorias & UI & UE & UCR & UATC & UD & UL & UDN & DCP & DCR & N. $\stackrel{\circ}{\text { de }}$ OP \\
\hline Indústria alimentar & 0 & 4 & 3 & 4 & 0 & 0 & 0 & 3 & 4 & 5 \\
\hline Indústria de bebidas & 0 & 2 & 1 & 1 & 0 & 4 & 5 & 5 & 3 & 6 \\
\hline Indústria transformadora & 2 & 0 & 0 & 0 & 0 & 0 & 2 & 0 & 2 & 2 \\
\hline Telecomunicações & 1 & 6 & 6 & 6 & 0 & 2 & 0 & 6 & 7 & 9 \\
\hline $\begin{array}{l}\text { Comércio e reparação de } \\
\text { automóveis }\end{array}$ & 5 & 2 & 1 & 1 & 1 & 0 & 2 & 1 & 10 & 11 \\
\hline Actividade imobiliária/construção & 0 & 0 & 1 & 0 & 1 & 5 & 3 & 3 & 9 & 11 \\
\hline Superfícies comerciais & 1 & 4 & 3 & 3 & 0 & 0 & 2 & 7 & 6 & 9 \\
\hline Instituições financeiras & 0 & 1 & 0 & 0 & 0 & 0 & 0 & 1 & 1 & 1 \\
\hline Lazer & 0 & 1 & 1 & 1 & 0 & 1 & 0 & 1 & 1 & 2 \\
\hline Moda & 0 & 1 & 0 & 0 & 0 & 0 & 0 & 0 & 2 & 2 \\
\hline Outros & 0 & 0 & 0 & 0 & 0 & 1 & 1 & 1 & 2 & 2 \\
\hline
\end{tabular}

$\begin{array}{llll}\text { Legenda } & & & \\ \text { Sigla } & \text { Descrição } & \text { Sigla } & \text { Descrição } \\ \text { UI } & \text { Urbana industrial } & \text { UL } & \text { Urbana de lazer } \\ \text { UE } & \text { Urbana de escritórios } & \text { UDN } & \text { Urbana de diversão nocturna } \\ \text { UCR } & \text { Urbana de comércio a retalho } & \text { DCP } & \text { Densidade de circulação pedestre } \\ \text { UATC } & \text { Urbana de acesso a transportes colectivos } & \text { DCR } & \text { Densidade de circulação rodoviária } \\ \text { UD } & \text { Urbana de desporto } & \text { OP } & \text { Outdoors personalizados }\end{array}$

\footnotetext{
${ }^{1}$ Medidas de prioridade ao transporte público rodoviário na cidade do Porto [http:// www.cm-porto.pt/users/0/58/2f589e327a202 02922d8fc46511ba385.pdf, accessed 21/12/2010].

Mobilidade na cidade do Porto: análise das deslocaşões em transporte individual [http:// www.cm-porto.pt/users/0/58/Mobilidade nacidadedoPorto_4f52bfea48d0e1384a 7386078f378d5a.pdf, accessed 21/12/2010].
} 
Figura 1. Mapas de densidade de circulação pedonal e rodoviária e das zonas urbanas em estudo com a respectiva localização dos Outdoors personalizados

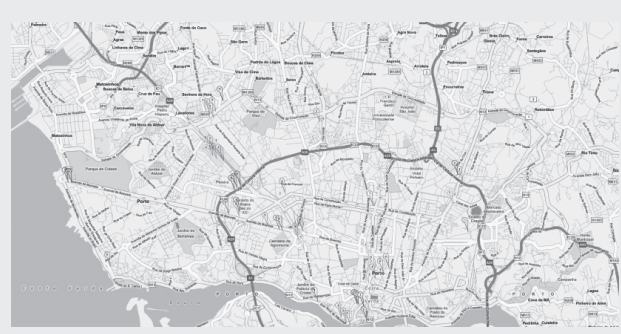

Mapa de localização dos outdoors personalizados

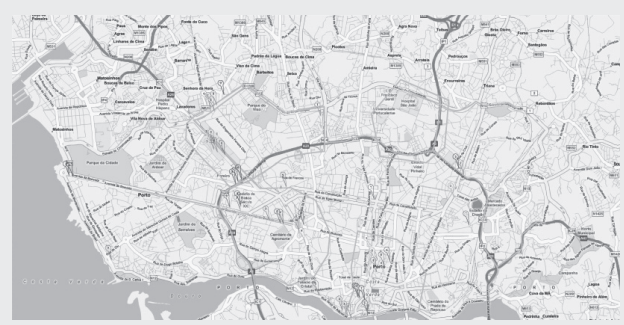

Mapa da densidade de circulação rodoviária (inclui a localização dos outdoors personalizados)

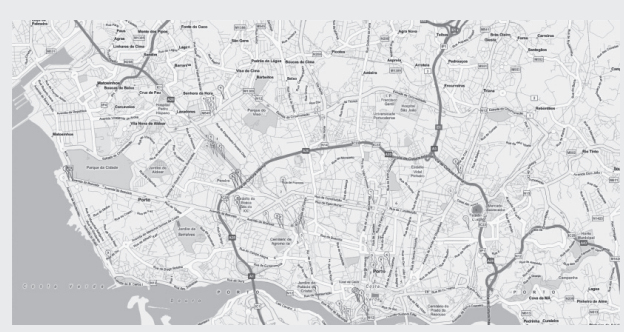

Mapa da zona urbana de comércio a retalho (inclui a localização dos outdoors personalizados)

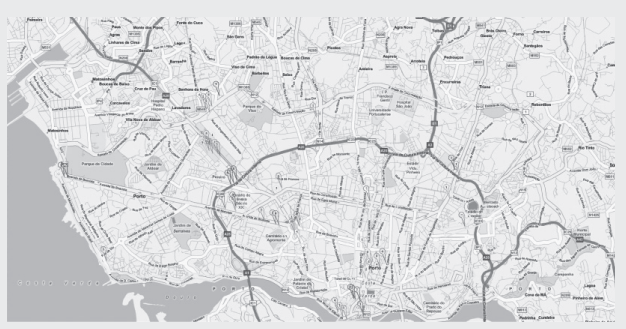

Mapa da densidade de circulação pedonal (inclui a localização dos outdoors personalizados)

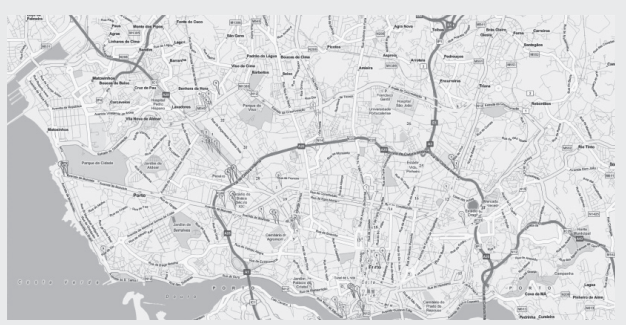

Mapa da zona urbana de acesso a transportes (inclui a localização dos outdoors personalizados)

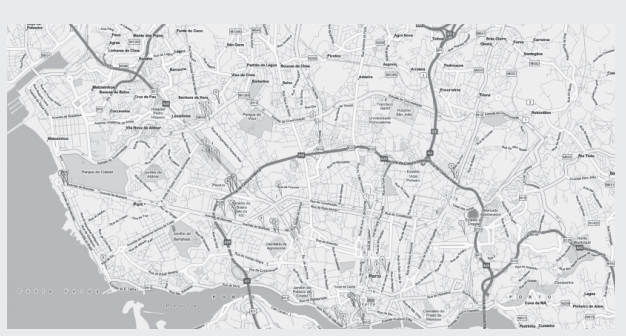

Mapa da zona urbana de escritórios/serviços (inclui a localização dos outdoors personalizados)

Os dados recolhidos, a par do cruzamento entre o mapa de localização e os mapas de densidade de circulação e também entre cada uma das zonas urbanas de actividade definidas, proporcionaram o acesso a informação pertinente para a realização deste estudo. Depois de analisados, os dados recolhidos possibilitaram a criação de uma base de estudo sobre o outdoor personalizado e o espaço envolvente; situação que se revelou fundamental para percepcionar o enquadramento físico, relacional e contextual do outdoor personalizado, considerando: 


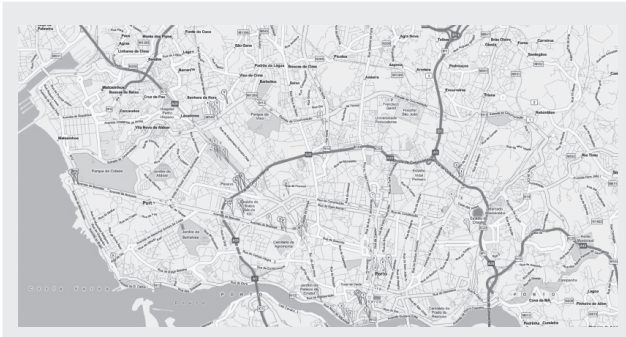

Mapa da zona urbana industrial (inclui a localização dos outdoors personalizados)

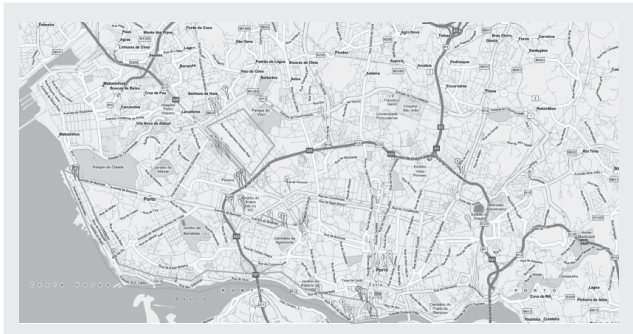

Mapa da zona urbana de diversão nocturna (inclui a localização dos outdoors personalizados)

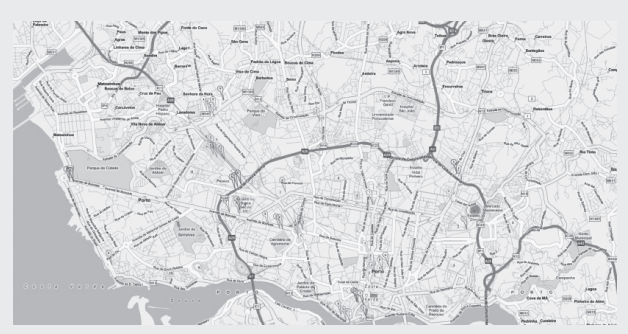

Mapa da zona urbana de desporto (inclui a localização dos outdoors personalizados)

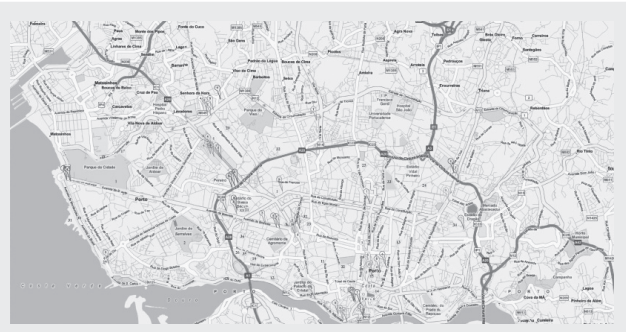

Mapa da zona urbana de lazer (inclui a localização dos outdoors personalizados)

- a presença nas grandes vias de acesso à cidade do Porto;

- a relação estabelecida entre cada zona urbana e público e a categoria de maior presença;

- o diálogo entre o outdoor personalizado e os elementos envolventes;

- a localização privilegiada para a colocação de outdoors personalizados.

\subsection{Discussão dos resultados}

Nas principais vias de acesso à cidade não verificámos a presença de outdoors personalizados. Caso o percurso incluísse somente a Via de Cintura Interna (VCI), o condutor apenas observava um outdoor. Esta situação pode dever-se ao facto de se tratar de uma via cujo limite de velocidade é de $90 \mathrm{~km} / \mathrm{h}$, envolvida por uma zona de protecção especial, na qual a construção não é permitida, ficando limitada aos prédios existentes antes da construção da VCI. Por outro lado, o licenciamento de colocação de publicidade ${ }^{2}$ é responsável por limitar o número de suportes de afixação dos outdoors personalizados nestas áreas.

\footnotetext{
${ }^{2}$ Para mais informação ver o disposto na alínea f, do artigo 8..$^{\circ}$ do Decreto-Lei n.o $13 / 1971$ de 23 de Janeiro, com a seguinte redacção: "1. É proibida a construção, estabelecimento, implantação ou produção de: f) Tabuletas, anúncios ou quaisquer objectos de publicidade, com ou sem carácter comercial, a visibilidade, salvo no que se refere a objectos de publicidade colocados em construções existentes no interior de aglomerados populacionais e, bem assim, quando os mesmos se destinem a identificar instalações públicas ou particulares.
} 
Nas zonas urbanas cujo acesso era, naturalmente, condicionado pela especificidade da(s) actividade(s) desenvolvida(s), o número de outdoors personalizados apresentou-se reduzido e limitado às actividades presentes. Salientam-se apenas as zonas de maior fluxo: "urbana de acesso a transportes colectivos", "urbana de escritórios/serviços" e "urbana de comércio a retalho", por compreender a presença de um maior número de outdoors personalizados. Porém, uma situação que merece destaque prende-se com o número elevado de outdoors na zona urbana de diversão nocturna (cerca de quinze). No entanto, esta situação pode dever-se ao elevado fluxo viário diurno. Com base nas densidades de circulação pedestre e rodoviária, constatámos uma clara superioridade, em número, dos outdoors localizados nas vias de maior fluxo rodoviário. No entanto, se se excluir a zona "urbana industrial" e a Estrada Exterior da Circunvalação envolvente, fica claro que a larga maioria dos outdoors personalizados encontravam-se situados na zona interna à VCI. Face aos dados analisados, concluímos portanto que as categorias de “comércio e reparação de automóveis", “actividade imobiliária/construção" e "moda” eram dirigidas, exclusivamente, para os automobilizados, relativamente aos pedestres, a categoria "indústria de bebidas" era a que apresentava maior representatividade. É de salientar que as restantes categorias eram partilhadas por ambos os públicos.

Da amostra de sessenta outdoors personalizados, observámos que quarenta (cerca de $70 \%$ ) apresentavam características que justificavam o estabelecimento de uma relação com o contexto onde estavam inseridos. O grau de fusão percebido, entre o outdoor e os elementos circundantes, variava de acordo com a complexidade da paisagem urbana e os suportes de afixação disponíveis (ou disponibilizados). Em zonas caracterizadas por uma maior densidade rodoviária e, também, por um elevado número de prédios urbanos, em particular, na Baixa, na Boavista, na parte oriental da Avenida da Boavista, na rotunda AEP e no centro histórico da Ribeira, verificámos que o diálogo entre o meio publicitário e a estrutura de afixação foi objecto de uma reflexão mais intensa. Precisamente, observámos que era necessário conjugar variáveis de modo a tornar a exposição da mensagem publicitária interessante para o público, considerando os fluxos rodoviários e pedestres, os suportes de afixação, a visibilidade, a legibilidade e até a dimensão.

$\mathrm{Na}$ sua reflexão sobre a orientação dos indivíduos na cidade, Lynch (2008) concluiu que as pessoas buscam elementos urbanos passíveis de serem reconhecidos, classificando-os como conteúdos identificativos do espaço citadino. Considerando o número elevado de obstáculos visuais caracterizadores do espaço envolvente, a presença de diversos edifícios em altura e a perpendicularidade das vias, limitadores do campo visual, o outdoor personalizado aí presente mantinha o estabelecimento de uma relação de harmonia visual com os elementos envolventes, sem no entanto perder o seu cariz marcadamente singular.

A configuração visual do espaço urbano interfere na definição estratégica e no planeamento da inserção do outdoor personalizado. Por se tratar de um meio com elevada dependência do suporte de fixação (fachadas, empenas e muros), torna-se fundamental conjugá-lo com os elementos envolventes, conforme se pode visualizar na Figura 2 (p. seguinte). Porém, não se pode colocar de parte a ideia de que alguns outdoors personalizados 
Figura 2. Diálogo entre alguns outdoors personalizados e elementos envolventes
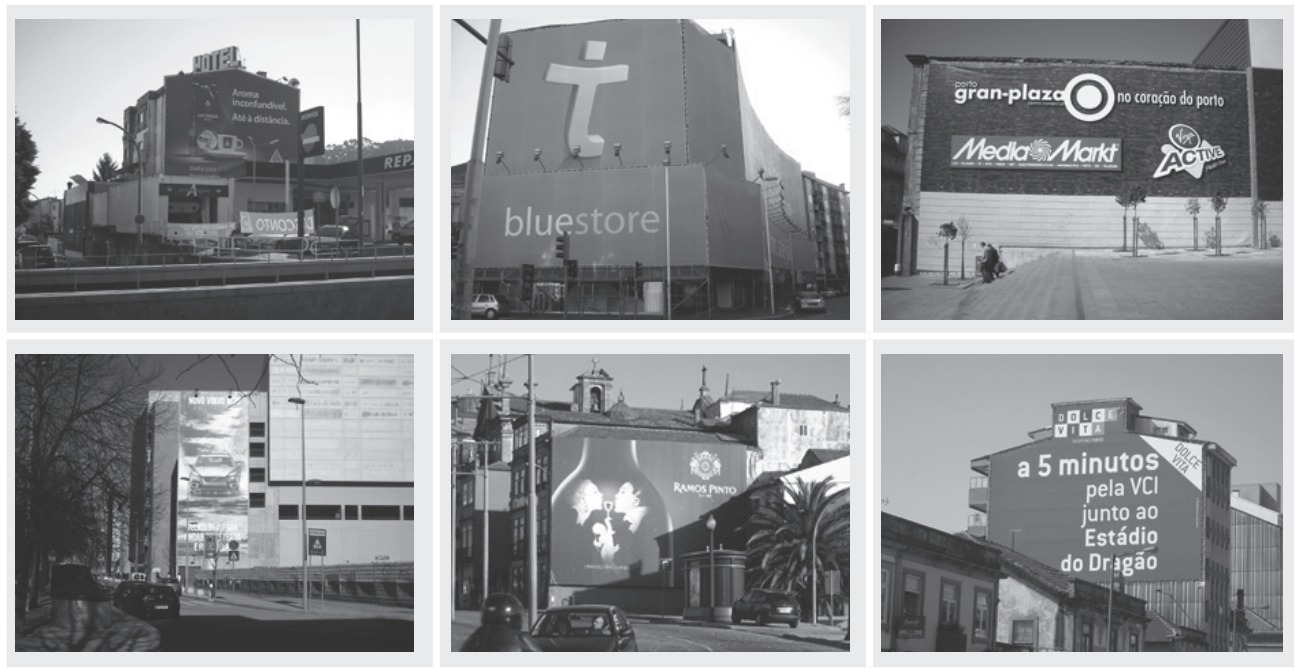

poderão ser reutilizados. Significa portanto, que a reflexão sobre o estabelecimento de um diálogo com o ambiente envolvente é, praticamente, inexistente, tornando a sua conjugação com o local de inserção menos praticável.

A partir da reflexão de Cullen (2008), sobre a pertinência dos elementos arquitectónicos enquanto potencial de atracção visual e de impacto emocional, observámos que os gavetos e os outdoors personalizados afixados em estruturas elevadas são pontos de convergência do olhar, assinalando o local; da mesma forma que os inseridos em zonas com exposição privilegiada ou no campo visual gozam de uma disposição estratégica, levando ao estabelecimento de uma relação com o observador, conforme se pode observar na Figura 3.

Em síntese, percebemos a existência de espaços atraentes para a colocação do grande formato, particularmente, se se considerar as oportunidades criativas que tais locais possibilitam. A selecção de espaço para a colocação de um outdoor personalizado implica a ponderação sobre os efeitos visuais e comunicacionais proporcionados pela localização: visibilidade, notoriedade, relação com a identidade da marca.

\subsection{Reflexão}

O estudo permitiu entender a importância do envolvimento do outdoor personalizado no contexto urbano. No caso concreto da cidade do Porto, situado em grande número na parte interna da VCI, tem também presença em determinadas áreas como: a Baixa, a Praça de Mouzinho de Albuquerque ("rotunda da Boavista") e a zona mais oriental da Avenida da Boavista, a rotunda da AEP e o centro histórico da Ribeira. A categoria das "telecomunicações" tem maior presença em zonas de "acesso a transportes colectivos", de "escritórios/serviços" e de "comércio a retalho"; os da categoria de "comércio 
Figura 3. Locais de inserção do outdoor personalizado

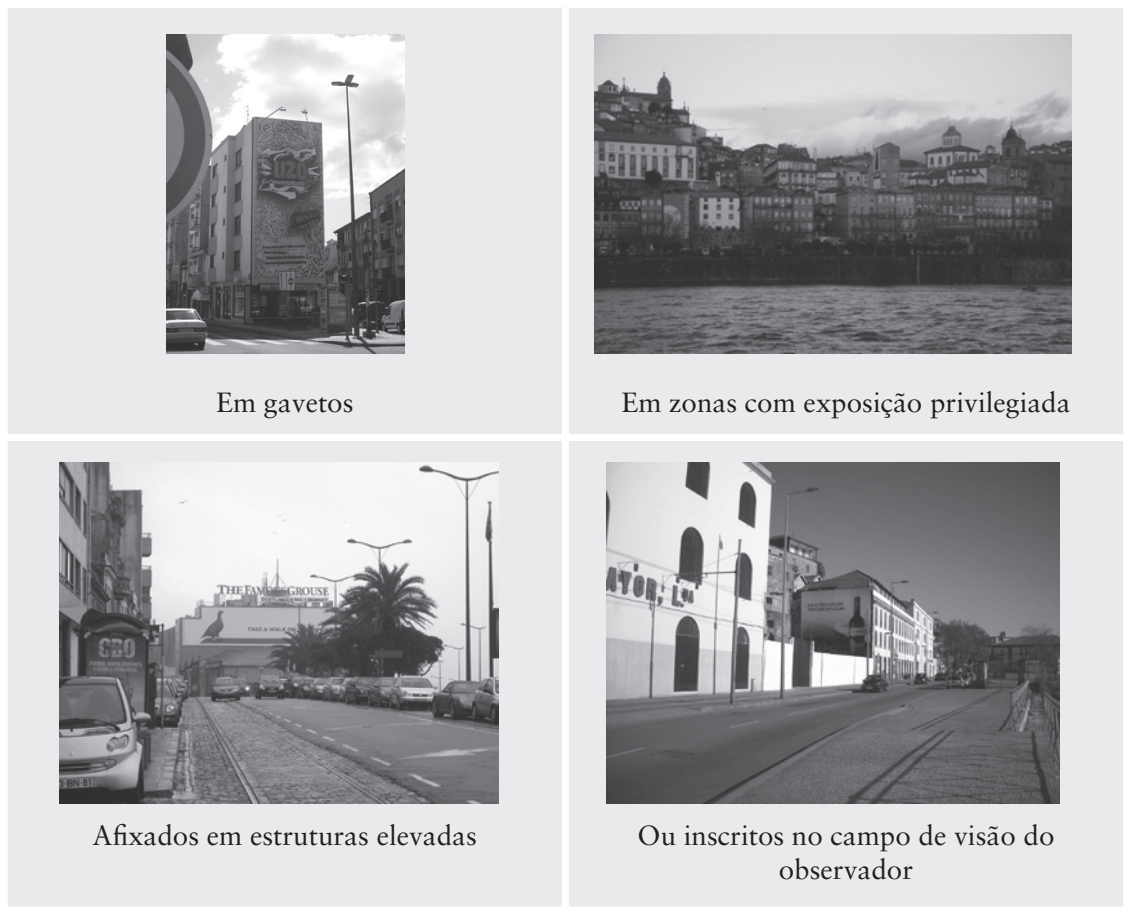

e reparação de automóveis" na zona "industrial" e de "deporto"; os de "actividade imobiliária e construção" nas zonas de "lazer" e "desporto"; e, finalmente, a "indústria de bebidas" perto de locais de "diversão nocturna". Quanto ao público, ficou evidente que os outdoors personalizados das categorias "comércio e reparação de automóveis", "actividade imobiliária e construção" e "moda" dirigem-se para os automobilizados e os da "indústria de bebidas" para os pedestres.

Gozando de liberdade na selecção dos pontos de fixação, procurando tirar partido de empenas, fachadas ou muros estrategicamente localizados, verificámos um envolvimento marcante da publicidade exterior de grande formato no espaço onde se insere, juntamente com os elementos mais próximos. Reconhecendo a importância estratégica inerente aos espaços de afixação dos outdoors personalizados, não é possível ignorar a elevada subordinação deste suporte face à estrutura. Contrariamente ao padronizado, que goza de espaços predefinidos e aprovados, a necessidade de uma empena, fachada ou muro de suporte (ou vedação) torna o personalizado dependente das estruturas disponíveis a par da obrigatoriedade da obtenção de licenças camarárias. Esta limitação pode tornar um espaço interessante para inserção de mensagens publicitárias numa situação difícil de alcançar (ou mesmo inalcançável). 


\section{Realidades paralelas: uma socialização híbrida}

Vivemos numa sociedade da informação catapultada pelas plataformas tecnológicas, especialmente quando falamos do ciberespaço ou simplesmente da Internet (Negroponte, 1995). Essa cibercultura que penetra no nosso quotidiano faz-nos transitar de forma híbrida em dois mundos, o real (físico) e o virtual (digital), na realização de tarefas quotidianas, na busca de informação, nos relacionamentos (Levy, 1999; Castells, 1999; Kerckhove, 1995).

Habitamos um mundo real e outro virtual, daí a afirmação de Ito (1997) de que os arquitectos e designers deveriam desenhar projectos para sujeitos de duplo corpo. Isso, porque nós contemporâneos estamos actualmente munidos de dois tipos de corpo para responder a estes dois tipos de natureza. O corpo real ligado ao mundo físico por meio de fluidos que correm por seu interior. E, o corpo virtual conectado ao mundo digital mediante fluxos. Na realidade estes dois corpos não estão separados, são parte do que constitui a presença física actual. (Picon, 2004, in Ortega, 2009: 75 )

Ao identificar tal fenómeno social e ao enquadrá-lo na perspectiva deste artigo discussão sobre a virtualização de elementos que compõem a experiência do indivíduo com o grande cartaz de rua através da plataforma online Bigposter -, compreendemos que neste cenário híbrido nos interessa mais olhar para o processo no sentido de que o mundo real, incluindo as cidades, está cada vez mais presente no mundo tecnológico, entenda-se no ciberespaço, do que o processo contrário, segundo o qual a tecnologia digital está cada vez mais presente nas cidades e espaços urbanos (Mitchell, 1999). Ambas as afirmações são pertinentes, mas, como exposto anteriormente, o objectivo do corpus do Bigposter está na recolha, publicação, acesso e troca de informações relevantes sobre o outdoor personalizado.

Antes de pensar na virtualização é preciso ter em atenção uma série de factores do mundo físico que influenciam a experiência com o outdoor personalizado. O indivíduo, para além da percepção visual, é incentivado por uma mistura de sentidos relacionados com ambiência, fluxo de pessoas, trânsito de veículos, mensagem visual, mensagem linguística, entre outros. Neste sentido, ponderamos três categorias de análise: a sua localização na cidade, já aflorada; a sua visualização na óptica do observador e a sua ambiência no espaço público.

A pensar exclusivamente no ciberespaço, citamos as sete características fundamentais da comunicação na Internet, propostas por Schultz (1999): multimedialidade, interactividade, hipertextualidade, ubiquidade/globalidade, velocidade/instantaneidade, memorização e personalização. Destacamos a interactividade como agente importante para a alteração do comportamento passivo do consumidor de conteúdos para assumir uma condição activa, focada na busca dos interesses particulares através de caminhos não-lineares estruturados sob a lógica de navegação por computadores. Nesta perspectiva, podemos remontar a ideia de que os meios de comunicação são extensões do homem (McLuhan, 2004). 


\subsection{Um olhar para a publicidade exterior em mundos virtuais}

Ao assumir que as cidades tomam o caminho tecnológico não apenas no sentido de aplicar tecnologias digitais nas estruturas urbanas, mas no sentido de que as cidades, suas rotinas, tarefas quotidianas e relacionamentos estão cada vez mais presentes no ciberespaço, a publicidade exterior enquanto elemento da urbe, agente formador da opinião na esfera social, pode tirar proveito das características intrínsecas ao meio virtual para diversas finalidades: mapear a publicidade que está integrada no espaço urbano, facilitar a programação estratégica de marketing e publicidade de uma marca, promover o serviço das produtoras de publicidade exterior, integrar a experiência da publicidade exterior em mundos virtuais simuladores da cidade e da vida real e, especialmente, para o caso do portal online Bigposter, servir como um instrumento que torne mais performativa a acção de pesquisadores e profissionais que pretendam estudar, analisar e discutir os diversos assuntos associados à temática do projecto.

Assim, e com o intuito de identificar tendências em narrativas multimediáticas, consideramos interessante olhar para a presença da publicidade exterior no ciberespaço em dois sentidos:

- publicidade emuladora do outdoor, equivalente a um simulador virtual da vida real, que modela a experiência virtual à semelhança do espaço físico (videojogos, simuladores, metaversos - Second Life);

- publicidade representativa do outdoor, equivalente a peças publicitárias em cenário web com diferentes linguagem e roupagem, mas que tenha algum tipo de ligação a componentes da essência conceptual da publicidade exterior (banner online, pop-up).

A primeira categoria condiz com os modelos virtuais emuladores do espaço físico, num ensaio lúdico da realidade capaz de convencer o ciber-observador de que o cenário "verdadeiro" é igual, ou muito próximo, do sistema interactivo. No Second Life, simulador 3D da vida real no ciberespaço, além do humano (avatar), da cidade (palco digital) e dos relacionamentos (rede social), a publicidade exterior espalha-se pelas estruturas ciber-urbanas. Neste caso, em que o outdoor assume um formato de comunicação semelhante ao mundo físico para as mais variadas funções (publicitária, cultural, informativa, política, etc.), anotamos como relevante a possibilidade de utilizar a tecnologia 3D na representação gráfica de situações espaciais e ambientais complexas na observação do outdoor personalizado. O carácter lúdico na galáxia dos videojogos também é propício para a reconstrução de cenários físicos que servem como palco para uma relação avançada entre homem e máquina. Por exemplo, nos videojogos de futebol, os estádios dos clubes possuem cartazes que contribuem para o realismo da experiência ao configurar o conteúdo espacial de acordo com a percepção visual que o humano tem do cenário real. Mais do que reproduzir a arquitectura do estádio, os digital games utilizam anunciantes reais nos adboards afixados no palco de acção (in-game advertising) (Carless, 2006).

A segunda categoria, "publicidade representativa do outdoor", refere-se a peças de comunicação online que não têm o formato da publicidade exterior, mas de alguma 
forma possuem elementos ou características semelhantes à essência do outdoor. Citamos o banner online como um tipo de anúncio que está localizado em locais de passagem, à semelhança do cartaz de rua, pois no ciberespaço navegamos por páginas web e não folheamos páginas web. Apesar de o banner online possuir semelhanças com o cartaz de rua - imagem em destaque, texto directo, localização estratégica -, não é correcto considerá-lo uma evolução de raiz. Dito isso, é sugestivo lembrar as sete características da comunicação no ciberespaço, referidas anteriormente, pois são uma maior valia no que se refere à criação de uma simulação com linguagem específica, que procura caminhos semelhantes ao real, mas que também utiliza os atributos das novas tecnologias para complementar a experiência em interface digital.

Expostas as duas categorias, destacamos que ambas possuem elementos pertinentes para a representação virtual do outdoor personalizado que se pretende desenvolver na plataforma Bigposter. Como exemplo, o conceito de simulação espacial da categoria "publicidade emuladora do outdoor" sugere uma configuração de cenário em três dimensões. Com a mesma atenção, também citamos a exposição de recursos multimédia (dados gráficos, audiovisuais, textuais, etc.) em profundidade não-linear, na categoria "publicidade representativa do outdoor", como outra solução narrativa adequada para integrar a composição da simulação.

Em relação à organização e à reprodução de todos os dados colectados no espaço físico pela equipa de investigação do portal online Bigposter, olhámos para o conceito do infográfico animado da produtora de publicidade exterior Goa Billboards ${ }^{3}$ como um modelo potencial para a integração desta panóplia de conteúdos fragmentados numa unidade informativa (foto, vídeo, texto, gráfico, mapa, ilustração 2D, animação 3D, etc.) (Cairo, 2005). O caso da produtora australiana é incentivador no sentido de valorizar a exposição de informações relevantes sobre as características das peças de comunicação: localização, audiência, dimensão, forma, mensagem, etc.

\subsection{Directrizes para a construção de um modelo virtual}

Conforme o exposto neste capítulo, acreditamos que uma hipótese para a transposição físico-virtual da temática do projecto deve ser guiada pelas seguintes directrizes (conforme Figura 4):

- localização do outdoor - fornecer dados que permitam conhecer o local em que a peça está afixada, seu formato, suas dimensões, o nome e o CAE, as cores predominantes, o produto e/ou serviço que anuncia, entre outras informações que auxiliam o reconhecimento da peça publicitária;

- visualização do outdoor - estamos convencidos de que a simulação do olhar do indivíduo durante a recolha de imagens é o caminho mais coerente para simular a observação da publicidade. Neste sentido, a fotografia é uma técnica adequada para emular a experiência da visão. Com uma lente de $50^{\circ}$, em plano horizontal, Cartier-Bresson (2005) parece obter o enquadramento mais rigoroso. Também, 
Figura 4. Registo das categorias localização, visualização e ambiência no mundo real e reproduzidas no virtual

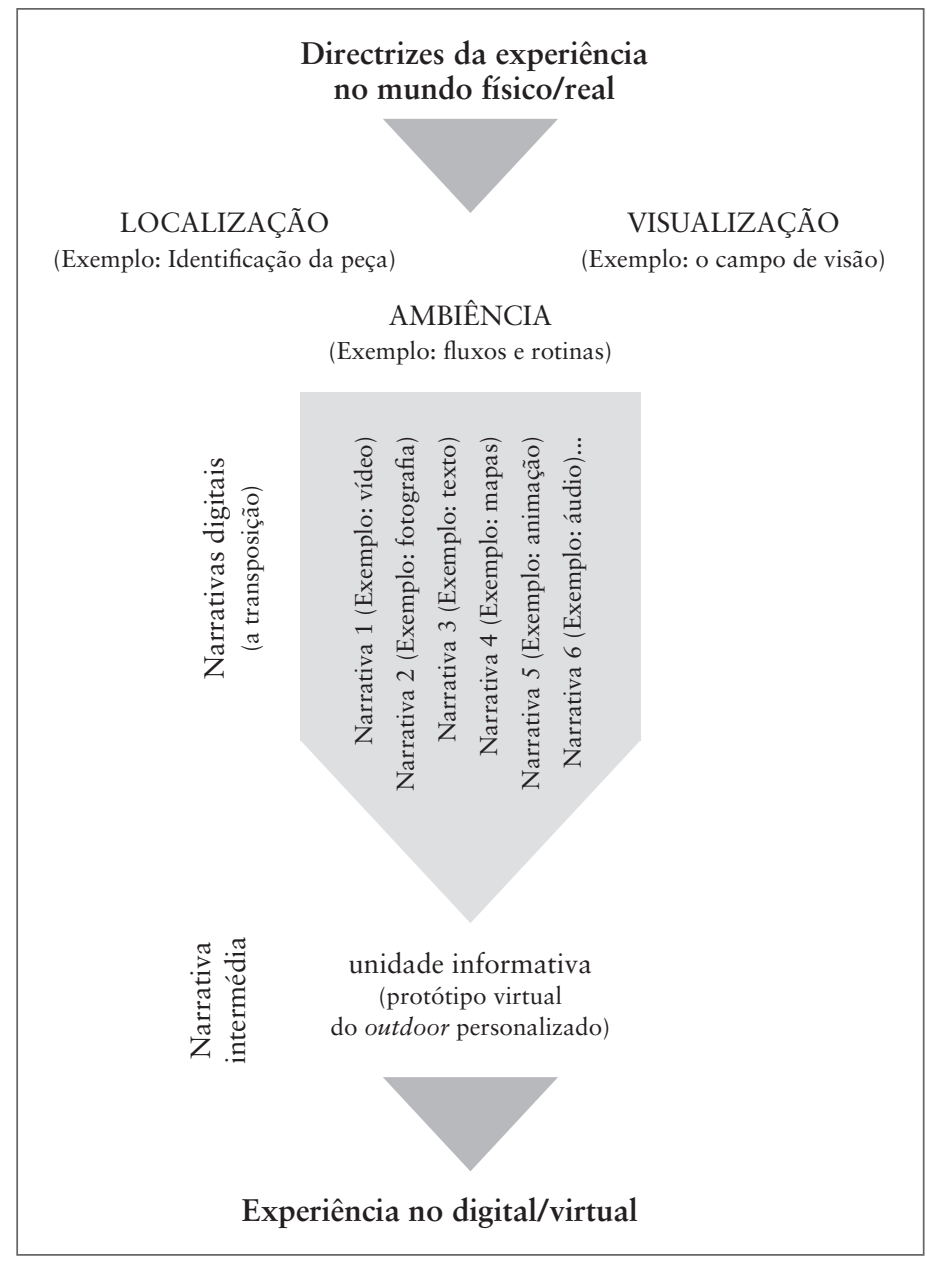

com regras de posicionamento, incluindo distâncias flexíveis e ângulos de visão fixados em $30^{\circ}, 90^{\circ}$ e $150^{\circ}$, Lynch (2008 in Viana, 2009) explica que é possível fazer três registos fotográficos de um outdoor de forma a abranger os principais pontos de visão dos indivíduos;

- ambiência do outdoor: para fornecer um melhor entendimento do objecto em análise, um vídeo com duração de quinze segundos será efectuado no local. O objectivo desta ferramenta é registar informação de movimento, luz e som no cenário original para apresentação no portal online. Numa perspectiva mais profunda, será desenvolvido um infográfico para cada outdoor da base de dados online. Esta imagem consistirá em diversos fragmentos multimédia (imagem, 
vídeo, texto, ilustração $2 \mathrm{D}$, animação $3 \mathrm{D}$, cartografia, etc.) unificados numa narrativa com informações e simulações relevantes sobre a peça publicitária e elementos urbanos que possam intervir na mesma zona de acção.

Além de se centrar nestas directrizes, que identificam categorias de análise e seus itens de composição, consideramos que a próxima etapa sobre a virtualização da experiência da publicidade exterior, especificamente do outdoor personalizado, deve centrar-se na definição dos itens importantes de cada uma das três directrizes sugeridas neste estudo. Mais do que isso, após a definição dos dados e acções a serem transpostos do físico para o virtual, a pesquisa deverá pensar na recolha e registo de cada elemento (vídeo, fotografia, ilustração, animação, etc.), bem como na reprodução dos mesmos em interface digital.

\section{Conclusão}

O outdoor personalizado está a marcar indelevelmente a publicidade contemporânea. A espectacularidade de formatos, do tamanho de imagens que veicula e da frequência crescente no espaço público, são, entre outras, razões que justificam interesse de análise.

Ao longo desta breve reflexão tentámos aflorar alguns dos assuntos que nos parecem mais relevantes, no contexto desta publicação. Ou seja, a semântica da terminologia utilizada e a base de dados online; os parâmetros de localização na cidade do Porto e a transposição do espaço físico para o virtual.

Definido que foi o que entendemos ser o outdoor personalizado, assinalaram-se os parâmetros gerais do bigposter, portal de internet focalizado exclusivamente nos grandes cartazes de rua, que têm como principal característica serem idealizados, desenhados e produzidos para determinando local. São, neste contexto, imagens únicas.

A base de dados online de outdoors personalizados (http://bigposter.ufp.pt), a que fizemos referência no decorrer deste curto ensaio, é a grande plataforma que justifica este trabalho. Este instrumento permitir-nos-á contribuir para o estudo e problematização do outdoor personalizado e propagar o seu conhecimento para investigadores, estudantes, profissionais da área e outros interessados. A transposição do espaço físico para a plataforma virtual, que mereceu a nossa atenção, é um factor determinante na valorização do portal. Quanto melhor for efectuada, tanto melhores resultados obteremos, na medida em que teremos uma representação do mundo real mais fidedigna. Esta é uma das problemáticas importantes no contexto da valorização do portal Bigposter.

Face à ausência de qualquer reflexão no nosso país sobre a temática aqui proposta, pensamos justificar-se por si só este trabalho. Um trabalho estruturado, com interesse científico, académico e profissional que iniciamos no nosso país, com a pretensão de ser extensível a outras paragens. 


\section{Bibliografia}

Cairo, A. (2005) The Future Is Now: A recipe for telling stories online and how you can get there. [Em linha]. Disponível em: http://www.albertocairo.com/infografia/articulos/ 2006/design.html/ [Consultado em 21/12/2010].

Carless (2006) IGA's Townsend On BF2142 In-Game Ads. Gamasutra. Retrieved.

Cartier-Bresson, H. (2005) The Mind's Eye. In the Mind's Eye: Writings on Photography and Photographers (1. ${ }^{\text {e }}$ d., 1976). New York: Aperture.

Castells, M. (1999) A Era da Informação: Economia, sociedade e cultura. São Paulo: Editora Paz e Terra.

Cullen, G. (2008) Paisagem Urbana, Lisboa: Edições 70.

Le Goff, Jacques (1984) In Memória - História, Documento / Monumento, Lisboa: Imprensa Nacional-Casa da Moeda.

Jhally, S. (1995) Os Códigos da Publicidade, Porto: Ed. Asa, Comunicação /Acção.

Kerckhove, D. (1995) A Pele da Cultura. Lisboa: Ed. Relógio D’Água.

Kevin, L. (2008) A Imagem da Cidade, Lisboa: Edições 70.

Lévy, P. (1999) Cibercultura. São Paulo: Editora 43.

McLuhan, M. (2005) The Medium is the Message. Corte Madera: Gingko Press.

Medidas de prioridade ao transporte público rodoviário na cidade do Porto. [http:// www.cm-porto.pt/users/ 0/58/2f589e327a20202922d8fc46511ba385.pdf, accessed 21/12/2010].

Mesquita, F. (2006) Um Processo Completo para a Resposta Rápida e Personalizada na Estamparia Digital de Grande Formato: Uma abordagem à publicidade e exterior. [http:// repositorium.sdum.uminho.pt/ handle/1822/7307 accessed 21/12/2010].

Mitchell,W. (1999) E-topia.Urban Life Jim, but Not as We Know It. Boston: MIT Press.

Mobilidade na cidade do Porto: análise das deslocações em transporte individual. [http:// www.cm-porto. pt/users/0/58/Mobilidade nacidadedoPorto_4f52bfea48d0e1384a 7386078f378d5a.pdf, accessed 21/12/2010].

Moles, A. (1969) O Cartaz. Debates, São Paulo: Editorial Perspectiva.

Negroponte, N. (1995) Ser Digital. Lisboa: Editora Caminho.

Picon, A. (2004) 'Architectural and the virtual. Towards a new materiality' in Ortega, L. (Ed.), 2009, La digitalización toma el mando. Barcelona: G.Gilli.

Schultz, T. (1999) Interactive Options in Online Journalism: A content analysis of 100 US newspapers. [http:// www.blackwell-synergy.com/doi/ abs/10.1111/j.1083-6101.1999.tb00331.x/, accessed 24/01/2008].

Viana, F. (2009) O Outdoor Personalizado na Cidade do Porto: Uma análise face à sua localização. [https:// bdigital.ufp.pt/dspace/bitstream/10284/1069/3/fernanda_viana ribeiro.pdf/, accessed in 21/03/2010]. 